\title{
Biochemical changes after consumption of mineral water from spring 3 in Baile Tusnad in experimentally induced alcoholic liver disease
}

\author{
Gabriela Dogaru1, Marieta Motricală², Akos Molnar², Ioana Stănescu ${ }^{1}$, Adriana Bulboacă ${ }^{1}$, Lorena \\ Ciumărnean', Vasile Rus ${ }^{3}$
}

Corresponding author: Vasile Rus, E-mail: vasile.rus@usamvcluj.ro,

\section{1. "Iuliu Hatieganu" University of Medicine and Pharmacy Cluj-Napoca, Romania}

\begin{abstract}
Introduction. Mineral waters are administered in medical hydrology as prophylaxis or treatment, both internal and external. The mineral water from spring 3 in Baile Tusnad, with a total mineralization of $3351.0 \mathrm{mg} / 1$, is recommended in chronic liver diseases. From the point of view of its chemical composition, it contains sodium chloride, iron, carbon dioxide, traces of iodine, boron. Some studies have evaluated the therapeutic properties of mineral water as a whole, but it is considered that the different components of the waters may also act in an antagonistic manner. Material and method. For the experimental study, 25 white rats were used. The animals were assigned to 3 groups: group I - negative control, 5 animals; group II - positive control, 6 animals; group III - experimental group, 14 animals. Group I animals received tap water (50-75 ml/animal/day) throughout the experiment; group II and III animals received $12 \%$ ethyl alcohol (12-15 ml/animal/day) during the first 70 days. Over the last 30 days, group II animals received tap water (50$75 \mathrm{ml} /$ animal/day), while group III animals were administered mineral water from spring 3 in Baile Tusnad (50-75 $\mathrm{ml} /$ animal/day). Before starting alcohol administration, at 70 days, after alcohol administration, and at 100 days, after administration of tap water and mineral water for 30 days, $0.1 \mathrm{ml}$ serum/blood sample from each animal was collected in order to determine the values of some biochemical components: transaminases, glycemia, total protein, urea, creatinine, sodium, calcium, iron, potassium. Results and discussions. Transaminases, particularly aspartate aminotransferase (ASAT), increased after alcohol consumption, but after mineral water consumption for 30 days, they decreased more compared to the group that drank only tap water. Renal function was not affected. There were slight increases in glycemia and total protein values after alcohol administration, which decreased after water administration. During the study, the blood iron value statistically significantly increased at 100 days compared to day $70, \mathrm{p}<0.005$. Sodium (Na) and potassium (K) values increased on day 70 after alcohol consumption, but on day 100 they decreased to normal in both groups. A slight increase in calcium ion $(\mathrm{Ca})$ levels was observed in the group that consumed mineral water compared to the group that drank tap water, but without statistical significance. Conclusions. Both the indications and the methods of treatment are based on pharmacodynamic effects in the pre-absorption phase and after absorption of the water in the digestive tract. However, administration of mineral water requires careful monitoring of some biochemical components after its consumption.
\end{abstract}

Key words: carbonated mineral water, liver, experimental studies, sodium, iron, calcium, biochemistry

\section{Introduction}

Mineral waters are administered in medical hydrology as prophylaxis or treatment, both internal, in the form of drinking therapy or crenotherapy, and external. The mineral water from spring 3 in Baile Tusnad is used for internal treatment in chronic diseases such as digestive, hepatobiliary, renal, metabolic diseases, based on the specialist doctor's prescription. In persons with risk factors for digestive disorders, with an inadequate diet and consumption of irritating foods (alcohol, coffee, spices) or exposed to stress, it is indicated as primary prophylaxis, as health treatment for digestive rest. Hepatobiliary disorders are currently on the increase, being mainly favored by increasing environmental pollution, alcohol consumption and synthetic drugs. Baile Tusnad resort is situated in the south of Ciuc depression, at an altitude of 625-655 $\mathrm{m}$ [1].

The mineral water from spring 3 in Baile Tusnad, with a total mineralization of $3351.0 \mathrm{mg} / \mathrm{l}$, is recommended in chronic liver diseases, hepatic steatosis. From the point of view of its chemical composition, it contains sodium chloride, iron, carbon dioxide, traces of iodine, boron. Its beneficial effects 
are attributed to the presence of anions and cations in its composition, to their concentration [2]: the mineral water contains sodium chloride $(\mathrm{Cl}$ ions $617 \mathrm{mg} / \mathrm{l})$, HCO3 $378.2 \mathrm{mg} / 1$, traces of bromine, sodium 288 $\mathrm{mg} / \mathrm{l}$, potassium $76 \mathrm{mg} / \mathrm{l}$, magnesium $35.5 \mathrm{mg} / \mathrm{l}$, iron (Fe $17.3 \mathrm{mg} / \mathrm{l}$ ), carbon dioxide (CO2 $1647.0 \mathrm{mg} / \mathrm{l}$ ), calcium (Ca $93.8 \mathrm{mg} / \mathrm{l})$, boron, traces of iodine. It is acidulous, with a $\mathrm{pH}$ of 6 and a temperature of $14.5^{\circ} \mathrm{C}$ $[3,4,5]$.

Health improvement and prophylactic action are the major objectives of the therapeutic use of natural factors in spa resorts. Hydromineral therapy by ingestion, crenotherapy, is mainly intended for digestive, metabolic and urinary tract disorders. Both the indications and the methods of treatment are based on pharmacodynamic effects in the preabsorption phase and after absorption of the water in the digestive tract [1]. Water and the mineral salts it contains are important in all vital chemical and physical processes. It is considered that any deviation by $+/-10 \%$ of the water, salts, each individual electrolyte, of the ratio between various anions or cations leads to severe disorders and possibly to death [1].

In the case of sulfurous mineral waters, the biological effects are attributed to the presence of sulfur, particularly in the form of hydrogen sulfide. This can be absorbed through several pathways, can penetrate the skin and certain mucosas, acting at cellular level in the skin as well as in some internal organs, being indicated in renal diseases, hypertension, nervous system disorders, diabetes mellitus [6]. A number of studies have evaluated the therapeutic properties of mineral water as a whole, but it is considered that the different components of the waters may also act in an antagonistic manner [6].

It is not only the chemical substances present in the mineral water that contribute to its effect; an important role is played by the physical properties and also the mode of administration of the water [7]. For example, carbonated mineral waters used as drinking therapy are considered to increase gastric acidity and secretion, intestinal peristalsis, to be absorbed very rapidly, and to enhance diuresis. There are studies that support a significant reduction in postprandial glycemia in subjects having ingested natural carbonated water, and a significant effect in decreasing serum total cholesterol and low-density lipoprotein (LDL) cholesterol levels. According to the authors, this effect is due to the increase, by osmotic mechanism, of intestinal excretion of bile acids, and to the enhanced synthesis of bile acids from serum cholesterol through the $7 \alpha$-hydroxylase pathway. The decrease in postprandial glycemia and the improvement of lipid metabolism after ingestion of sodium-rich highly carbonated water were demonstrated by another study, which supports the role of these waters in preventing cardiovascular disease and metabolic syndrome [2]. Carbon dioxide (CO2) from carbonated waters is linked to volcanic phenomena, which are also found in the Harghita area; this maintains the water-electrolyte balance of fresh mineral water. Its loss in the atmosphere and the contact of carbonated mineral water with air are followed by precipitation of iron, calcium and magnesium in the water $[2,8]$.

Ferruginous waters which are usually carbonated waters are considered to stimulate the activity of hematopoietic organs and lead to an increase in general metabolism [7]. Iron plays an important role in the organism. Ferruginous waters are administered as internal treatment only from the spring, during meals, because otherwise iron in contact with air becomes inactive. Only bivalent iron is active, being absorbed in the presence of $\mathrm{HCl}$ and vitamin $\mathrm{C}[2,8]$. Ferruginous waters are prescribed for internal therapy, their phamacodynamic effect being based on the presence of bivalent iron ( $\mathrm{Fe}++)$, which is very easy to assimilate and metabolically and enzymatically active, provided that gastric juice acidity is normal $[2,8]$.

It is considered that alcoholic drinks that represent $35 \%$ of daily beverage consumption can also be a source of minerals, for example iodine and iron (wine), selenium (beer), fluorine, calcium and copper (all alcoholic drinks). Calcium and fluorine would be the main minerals provided by the different types of water. However, the influence of the geographical origin of tap water on calcium and fluorine intake is important [9].

Material and method

For the experimental study, 25 male white Wistar rats with a weight of $350 \mathrm{~g}$ were used. They were kept under standard vivarium conditions according to European Directive 63/2010 and Law $43 / 2014$ on animal protection used for scientific purposes. The animals were euthanized by intramuscular injection of an anesthetic overdose (ketamine $10 \%$ and xylazine $2 \%$ ). This experimental study obtained the approval of the Ethics Committee 
of the University of Medicine and Pharmacy ClujNapoca no. 533/23.12.2015 and the approval of the Veterinary Health Authority no. 17/13.12.2016. Animal survival was $100 \%$ in all groups of rats. The animals were assigned to 3 groups: group I - negative control, 5 animals; group II - positive control, 6 animals; group III - experimental group, 14 animals. Group I animals received tap water (50-75 $\mathrm{ml} /$ animal/day) throughout the experiment; group II and III animals received 12\% ethyl alcohol (12-15 $\mathrm{ml} /$ animal/day) during the first 70 days. Over the last 30 days, group II animals received tap water (50-75 $\mathrm{ml} /$ animal/day), while group III animals were administered mineral water from spring 3 in Baile Tusnad (50-75 ml/animal/day). On experimental day 70,5 animals were euthanized ( 2 in group I, 1 in group II and 2 in group III), and on day 100, the rest of 20 animals were euthanized. Before starting alcohol administration, at 70 days, after alcohol administration, and at 100 days, after administration of tap water and mineral water for 30 days, $0.1 \mathrm{ml}$ serum/blood sample was collected from the retrobulbar sinus at the internal angle of the eye of each animal in order to determine the values of some biochemical components: transaminases, glycemia, total protein, urea, creatinine, sodium, calcium, iron, potassium. Statistical analysis was aimed at evidencing whether there were any statistically significant differences between the values obtained before and after treatment, either with tap water or mineral water. Data were collected and analyzed using Microsoft Excel 2007 application. The statistical significance threshold used was $\mathrm{p}<0.05$. Fragments in the form of $4 \mathrm{~mm}$ thick slices were taken from the liver of the euthanized animals for electron and optical microscopic histological examination [3, $4,5]$.

\section{Results and discussions}

Changes in the values of transaminases aspartate aminotransferase (ASAT) and alanine aminotransferase (ALAT)

There were increases in transaminase values after alcohol consumption, above the normal values, which decreased after water consumption, particularly after mineral water consumption for 30 days, returning close to normal, but without statistical significance, ASAT values being higher (Tables 1 and 2). When the energy metabolism of the hepatic cell is altered by infectious agents either through viral hepatitis viruses or toxic products, an increase in cell membrane permeability occurs, with the passage of cytoplasmic components into the serum (cytolysis). ALAT is the indicator of cytolysis and is indicated even for the detection of minimal hepatic lesions [10]. In the electron microscopic study, there was a marked increase in the smooth endoplasmic reticulum (SER) on day 70, which was abundant, in the form of many vesicles distributed throughout the hepatocyte cytoplasm, signifying a stimulation of lipid synthesis and a reduction of rough endoplasmic reticulum profiles, suggesting a decrease in the protein synthesis capacity. In some areas adjacent to the centrilobular veins, there were vacuolizations and even small necroses, so that in these areas the metabolic capacity of the liver was significantly reduced. After mineral water consumption, an increase in the number of lysosomes was found, which showed a mobilization of the defense capacity of hepatocytes against alcohol intoxication. A number of double nucleated hepatocytes were present, which indicates an increased hepatic regeneration capacity in response to the harmful action of a toxic agent, alcohol in this case $[3,4,5]$. It is considered that ALAT is less sensitive than ASAT in alcohol-induced liver disease [11]. In group II, a positive control, the diminution of the action of alcohol in time and tap water consumption led to the maintenance of reversible alcohol-induced changes, with many mitochondria with a normal appearance, the rough endoplasmic reticulum arranged as parallel profiles suggesting an enhancement of protein synthesis, and significantly diminished lipid droplets $[3,4,5]$. The only changes detectable by optical microscopy were present in the liver, accumulation of lipid droplets and capillary vascular congestion. The rest of the organs, kidneys, pancreas, stomach, included in the study showed no lesional aspects detectable by optical microscopy $[3,4,5]$. These data can suggest that the mineral water from spring 3 in Baile Tusnad has hepatoprotective properties, through its capacity to diminish the toxic action of alcohol in hepatocytes and to maintain the hepatic structure and function close to normal $[3,4,5]$. However, continuing this research with subsequent clinical studies is necessary. ALAT values ranged within normal limits (VN).

Table 1 - Comparative changes in ASAT values $(\mathrm{U} / \mathrm{L})$ for each of the groups formed in the experiment 


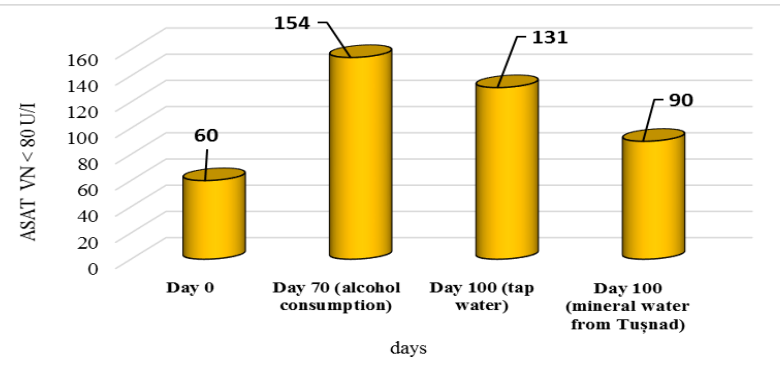

Table 2 - Comparative changes in ALAT values $(\mathrm{U} / \mathrm{L})$ for each of the groups formed in the experiment

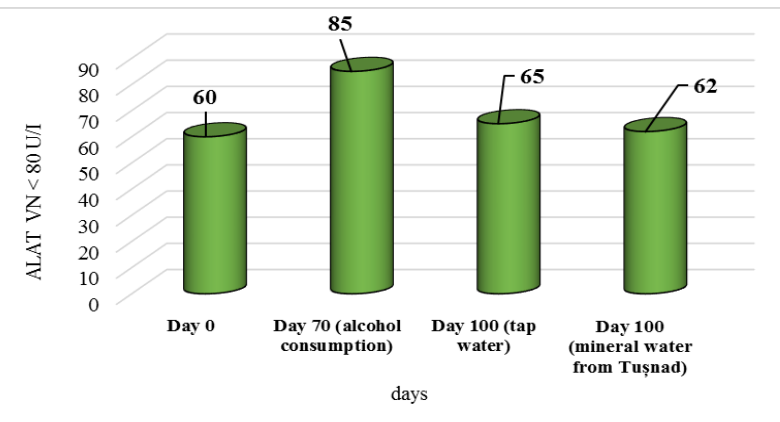

Changes in the renal function

As it can be seen in Tables 3 and 4, there were increases in urea and creatinine after alcohol consumption, without a histological alteration of the kidney structure. The values decreased, returning to normal after water consumption for 30 days, decreasing more in rats that drank mineral water from spring 3, but without statistical significance compared to those that consumed tap water.

Table 3 -Comparative changes in urea values $(\mathrm{mg} / \mathrm{dl})$ for each of the groups formed in the experiment

Table 4 - Comparative changes in creatinine

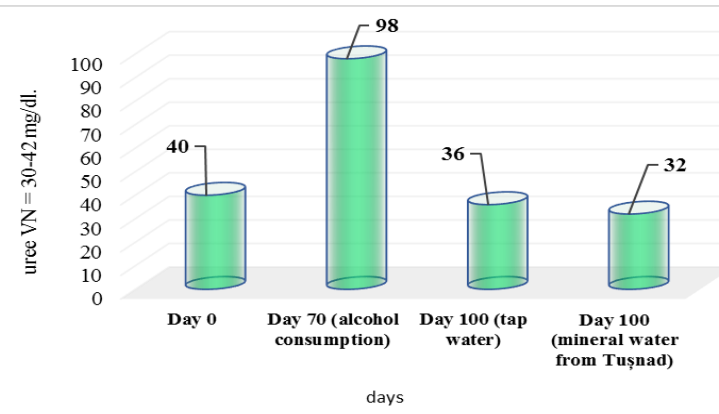

values $(\mathrm{mg} / \mathrm{dl})$ for each of the groups formed in the experiment

Changes in glycemia and total protein

During the experiment, there were slight increases in glycemia and total protein values after

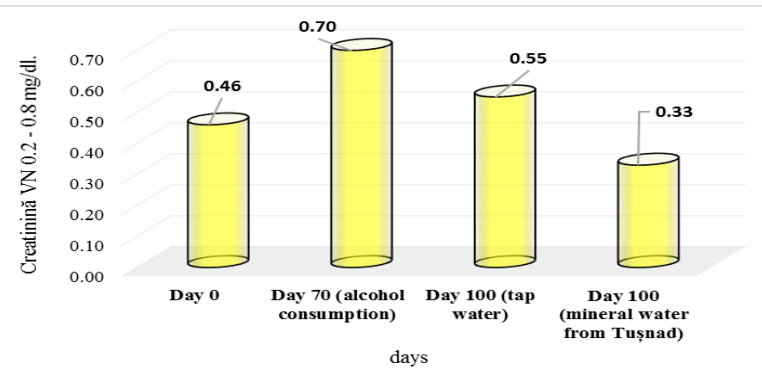

alcohol administration, which decreased after water administration, without statistical significance between the groups, the values ranging within normal limits for rats - Tables 5 and 6. In the electron microscopic study, a reduction of the protein synthesis capacity was observed in the liver after alcohol consumption $[3,4,5]$.

Table 5 - Comparative changes in glycemia values $(\mathrm{mg} / \mathrm{dl})$ for each of the groups formed in the experiment

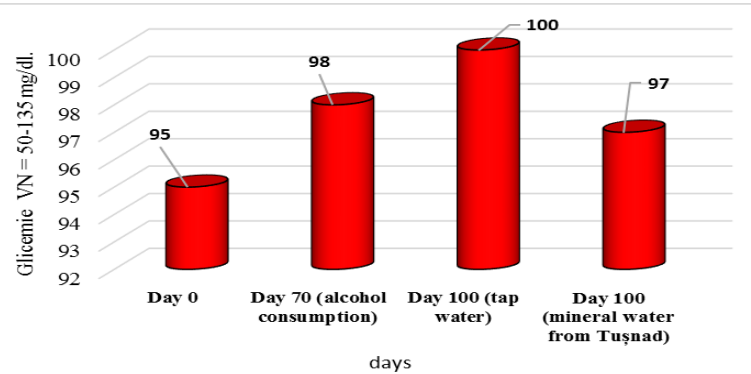

Table 6 - Comparative changes in total protein values $(\mathrm{g} / \mathrm{dl})$ for each of the groups formed in the experiment

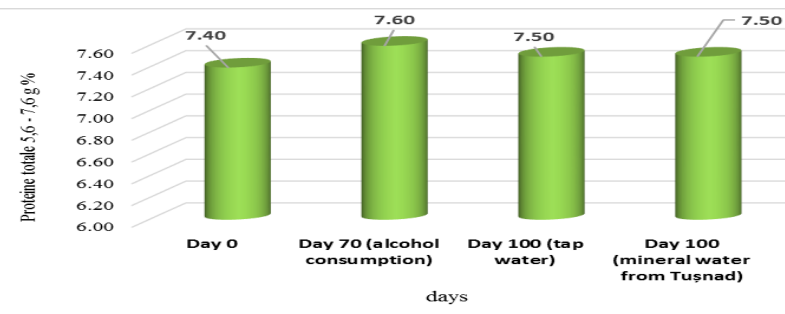

Changes in ions

According to the analysis report, the mineral water contains iron $(\mathrm{Fe})$, sodium $(\mathrm{Na})$, calcium $(\mathrm{Ca})$, along with other elements. During the experimental study, the blood iron value increased at 100 days compared to day 70 , with a statistically significantly higher absorption, $\mathrm{p}<0.005$ - Table 7 . The systemic absorption of iron is mainly regulated by the small bowel $[2,8]$. Monitoring of these values after 100 days might have been necessary. 
Table 7 - Comparative changes in Fe ion values $(\mathrm{mg} / \mathrm{dl})$ for each of the groups formed in the experiment

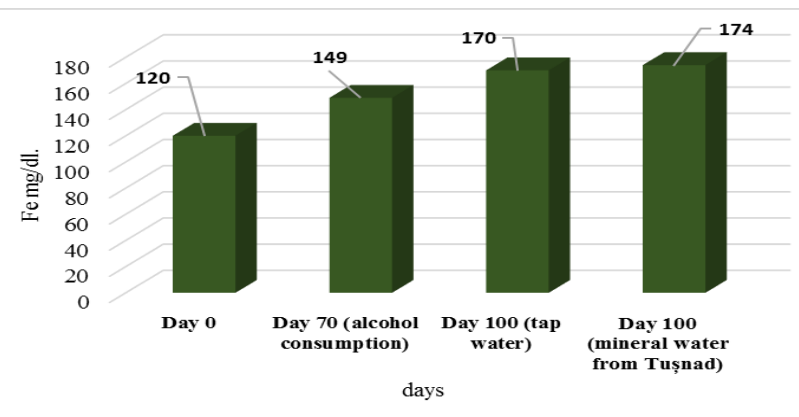

The values of sodium $(\mathrm{Na})$ and potassium $(\mathrm{K})$ increased on day 70 after alcohol consumption, but on day 100 they decreased to normal in both groups, without statistical significance between the group that drank tap water and the group that consumed mineral water, $\mathrm{p}>0.05$ - Tables 8 and 9 .

Table 8 - Comparative changes in $\mathrm{Na}$ values $(\mathrm{mmol} / \mathrm{l})$ for each of the groups formed in the experiment

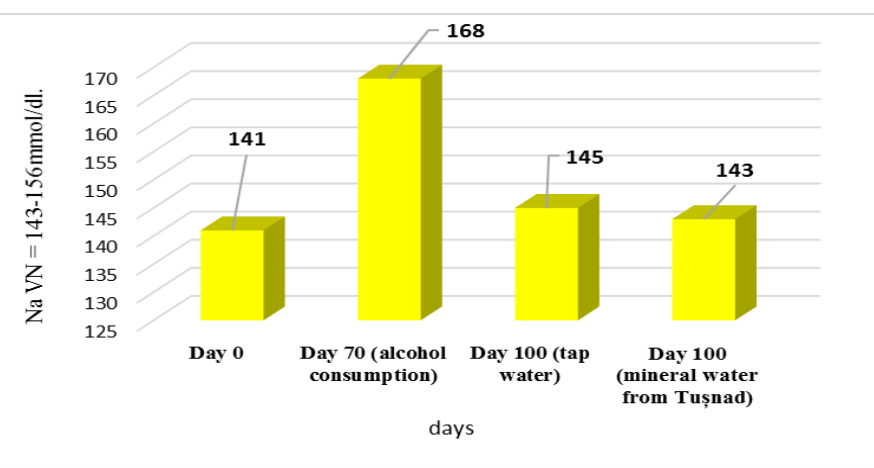

Table 9 - Comparative changes in $\mathrm{K}$ values $(\mathrm{mmol} / \mathrm{l})$ for each of the groups formed in the experiment

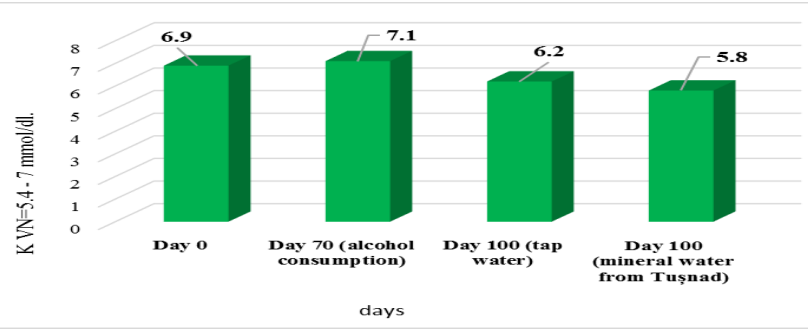

Regarding calcium ions $(\mathrm{Ca})$, there was a slight increase in the group that drank mineral water from spring 3, but without statistical significance compared to the group that drank tap water, $p>0.05$ - Table 10 .
Table 10 - Comparative changes in $\mathrm{Ca}$ values (mmol/l) for each of the groups formed in the experiment; throughout the experiment, the values were below the reference values of the laboratory where the analyses were performed.

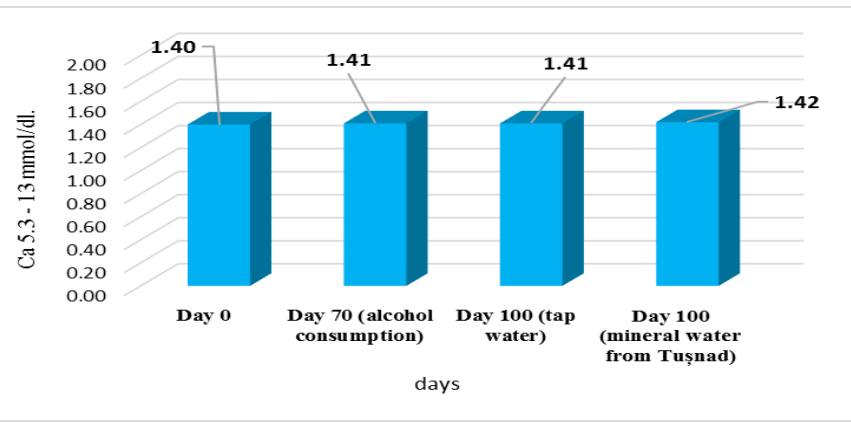

\section{Conclusions}

Transaminases, namely ASAT and ALAT, increased after alcohol consumption, while there were also cellular and subcellular changes in hepatocytes, but after mineral water consumption for 30 days, they decreased more compared to the group that drank only tap water.

The renal function or the kidney structure was not affected under optical microscopy.

There were slight increases in glycemia and total protein values after alcohol administration, which decreased after water administration, without statistical significance between the groups, the values ranging within normal limits for rats.

According to the analysis report, the mineral water from spring 3 contains iron $(\mathrm{Fe})$, sodium $(\mathrm{Na})$, calcium $(\mathrm{Ca})$, along with other elements. During the experimental study, the blood iron value statistically significantly increased at 100 days compared to day $70, \mathrm{p}<0.005$. Sodium $(\mathrm{Na})$ and potassium $(\mathrm{K})$ values increased on day 70 after alcohol consumption, but decreased to normal on day 100 in both groups. For calcium ions $(\mathrm{Ca})$, a slight increase was observed in the group that drank mineral water from spring 3 , but without statistical significance compared to the group that drank tap water.

After mineral water consumption, there were changes in some biochemical components, each playing an extremely important role in the organism. Monitoring these values beyond 100 days, as well as continuing this research with clinical studies might have been necessary. 


\section{References}

1. Elena Teodoreanu, Ovidiu Gaceu. Turism Balneoclimatic în România. Editura Universităţii din Oradea, 2013

2. Constantin Munteanu. Ape minerale terapeutice. Editura Balneară, Bucureşti, 2013

3. Gabriela Dogaru, Marieta Motricală, Molnár Ákos, Vasile Rus. Effects of mineral water from spring 3 in Băile Tuşnad on experimentally induced alcoholic liver disease. Balneo Research Journal. 2017;8(3):125-128

4. Gabriela Dogaru, Marieta Motricală, Molnár Ákos, Vasile Rus. An experimental study regarding the biological effects of mineral water from spring 3 in Băile Tuşnad on some organs after ethyl alcohol administration. Balneo Research Journal 2016, vol. 7 (1): 23-28.

5. Gabriela Dogaru, Ioana Stănescu, Adriana Bulboacă, Marieta Motricală, Vasile Rus, Constantin Crăciun, Septimiu Toader, Ioana Adela Rațiu. The therapeutic effect of mineral water from spring 3 in Baile Tusnad in experimental alcoholic liver disease in rats - an electron microscopic study. Balneo Research Journal. 2018;9(3):211-215

6. Jose Manuel Carbajo, Francisco Maraver. Sulphurous Mineral Waters: New Applications for Health. Review Article. Evidence-Based Complementary and Alternative Medicine. Volume 2017, Article ID 8034084, 11 pages. https://doi.org/10.1155/2017/8034084

7. Oscar Binștoc. Cura cu factori naturali în stațiunile balneo-climaterice și la domiciliu. Editura Medicală, 1963

8. Diana Munteanu, Delia Cinteză, Constantin Munteanu. Ape feruginoase. Editura Balneară, Bucureşti, 2012

9. Darret G, Couzy F, Antoine JM, Magliola C, Mareschi JP. Estimation of minerals and trace elements provided by beverages for the adult in France. Ann Nutr Metab. 1986;30(5):335-44
10. Jacques Wallach. Analizele de sânge. In Interpretarea testelor de diagnostic. Editura Știinţelor Medicale, România, ed. 7, 2001, 51-52

11. Frances Fischbach. Chemistry Studies. In A Manual of Laboratory and Diagnostic Tests. Lippincott Williams \& Wilkins, USA, 8 ed., 2009, 412-413. 